\title{
Comparative analysis of selected glass systems by dynamic simulation using measured real environmental conditions
}

\author{
Silvia Bizoňová ${ }^{1, *}$, Dušan Katunský ${ }^{1}$, and Miloslav Bagoňa ${ }^{1}$ \\ ${ }^{1}$ Department of Architectural Engineering of Faculty of Civil Engineering, Vysokoškolská4, 04200 Košice, Slovakia
}

\begin{abstract}
The subject of the study presents the measurement of temperatures on surfaces of glass systems of existing structures and the surfaces of experimental glass systems obtained by dynamic simulation. Measurements were made in the test cells of the Faculty of Civil Engineering of the Technical University of Košice. The partial results of which are the basis for the comparison of the currently installed and experimentally designed glass systems using spectrally selective films. The proposed mathematical-physical model was simplified by replacing the sash, frame and its components with a homogenous element with minimal shape modifications, while this does not have a significant effect on the simulation results. The choice of the proposed glass system respects the need for reduction of solar gains in summer and heat losses in buildings in winter through the weakest part of the building envelope and indicates future energy savings in relation to cooling and heating costs with a view to optimizing light and thermal comfort.
\end{abstract}

\section{Introduction}

Windows, despite the trend of improving their thermaloptical properties, are still the weakest part of the building and allow up to $40 \%$ of the building's total energy losses $[1,2]$. For this reason, it is essential to replace the low energy efficient window with a smart, more energy efficient and adaptable glazing $[3,4,5,6]$. Considering replacing/modifying existing building envelope structures, replacing a window is one of the simplest ways $[7,8]$. The concept of the appropriate selection of the type of spectrally selective layers in the glass system contributes to the increase of thermal comfort. At the same time it allows to reduce solar gains in summer by $50-60 \%$ [9]. According to the study [10] the reduction of energy by retrofitted double glazing is up to $8 \%$ of overall energy consumption. Due to its thermal and optical- properties, spectrally selective layers can be used even when the final thickness or weight of the structure is the decisive parameter. Replacing old glass systems with more energy efficient ones is one possibility of the envelope retrofit strategies [11]. The retrofitting idea is generally based on installation, fitting, or adaptation of transparent parts in older buildings. Renovation of windows is possible if the original sash and frame has satisfactory thermo-technical properties, which can be noticed already with threechamber PVC profiles. When considering replacing only such glass system instead of the full window element, it is known that the glazing area is several times larger than the sash therefore thermal properties of not heavy glazing are crucial for creation an interior thermal comfort. Based on the window retrofitting idea, it is necessary to quantify the improvement of the thermal- insulating properties in the renovation process. The aim of the study is to determine if added window film can change the energy-optical-thermal insulation properties of the selected glazing. If yes, how significant is the change of window parameters? Are the resulting properties desirable? The provable influence of selective layers can also be used in the design of new progressive glass systems whose heat transfer coefficient could be an approach to the improvement of external wall properties. Dynamic simulations applying measured data [12] or a reference year [13], are best suited for verifying the properties of structures over the investigated period.

\section{Window structure and its features}

The experimental test cell of the Faculty of Civil Engineering in Košice (see Fig. 1.) is equipped by a window in the measuring opening, which was the subject of other research in the past. The created database of measured temperatures was used in this study as a basis for numerical calculation and subsequent comparison of measured and calculated results.

The window of the experimental cell is oriented to the south. The proposed glass systems were compared in terms of surface temperatures with the existing triple glass system mounted in the plastic sash of the experimental cell window. In the measuring hole was seated six-chambered plastic window profile Rehau Geneo MD plus with depth of $86 \mathrm{~mm}$ and $U_{\mathrm{f}}=0.79 \mathrm{~W} /$ $\left(\mathrm{m}^{2} . \mathrm{K}\right)$. In the sash was mounted triple glazing Nitrasklo Climatop One (4-16-4-16-4 mm, argon 95\%), see Fig. 2.

These parameters were calculated in accordance with [14] and are presented in Table 1, 2. Material composition of glass systems are as follows:

\footnotetext{
* Corresponding author: silvia.bizonova@ $@$ tuke.sk
} 
1. Planitherm Ultra $\mathrm{N}(4 \mathrm{~mm}$; outer, inner pane); Planitherm One (4 mm, middle pane); gas filling: argon $95 \%+$ air 5\% (16 $\mathrm{mm} \times 2)$.

2. Planitherm Ultra N (4 mm; outer, inner pane); HM88 Twin Coat (0.076 mm; 2x); gas filling: argon $95 \%+$ air 5\% (12 mm x 3) or krypton 95\% + air $5 \%(12 \mathrm{~mm} \times 3)$.

3. Planitherm Ultra N (4 mm; outer, inner pane); Planitherm One (4 mm, middle pane); HM88 Twin Coat (0.076 mm; 1+1); gas filling: argon 95\% + air $5 \%$ or krypton $95 \%+$ air $5 \%(12 \mathrm{~mm} \times 2 \times 2)$.
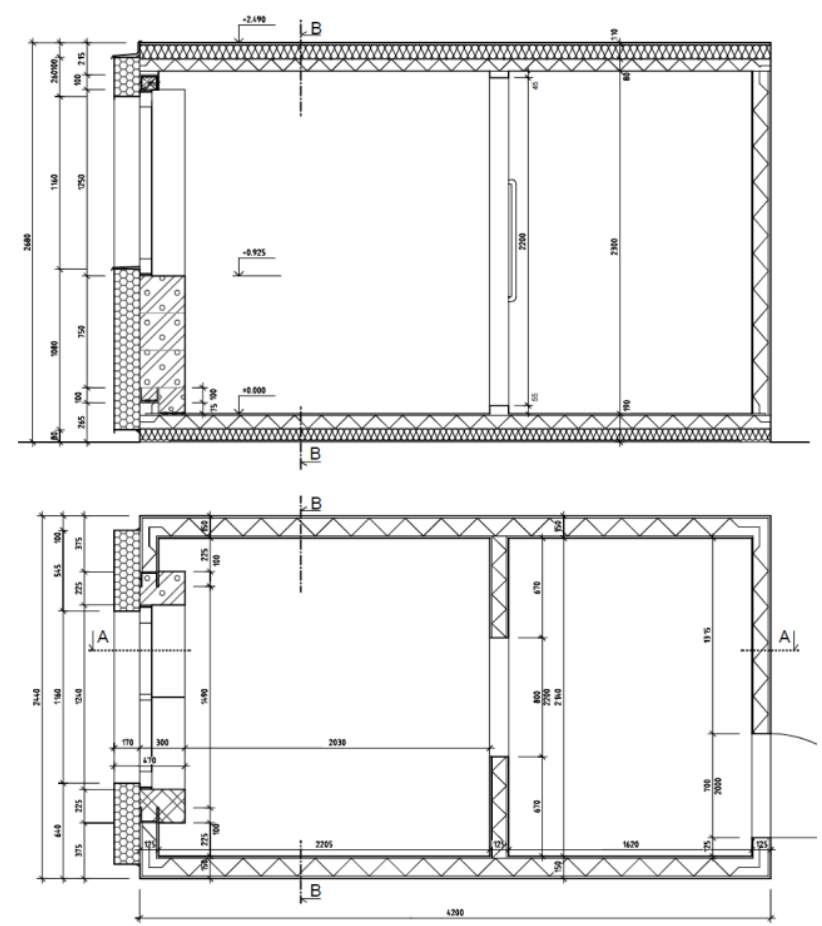

Fig. 1. Section and floor plan of experimental exterior cell

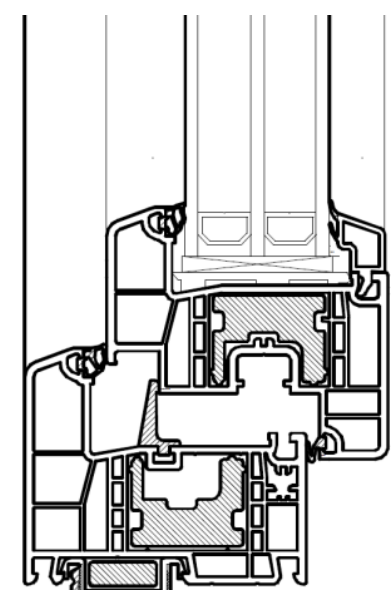

Fig. 2. The detail of the window structure located in the measuring hole of the external wall
Table 1.Solar and visible properties of used glass panes and window film

\begin{tabular}{|c|c|c|c|c|c|}
\hline \multicolumn{3}{|c|}{ Variable } & Planith. & Planith. & HМ \\
\hline \multirow{2}{*}{ 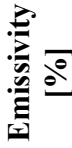 } & \multicolumn{2}{|c|}{ front } & 3.7 & 2.2 & 11.0 \\
\hline & \multicolumn{2}{|c|}{ back } & 83.7 & 84.0 & 10.5 \\
\hline \multirow{4}{*}{ 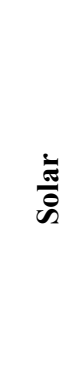 } & \multirow{2}{*}{ 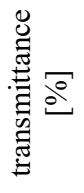 } & front & 58.5 & 47.8 & 50.6 \\
\hline & & back & 58.5 & 47.8 & 50.6 \\
\hline & \multirow{2}{*}{ 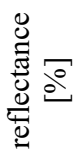 } & front & 29.3 & 45.6 & 29.1 \\
\hline & & back & 24.0 & 41.7 & 28.5 \\
\hline \multirow{4}{*}{$\begin{array}{l}\frac{0}{0} \\
\frac{0}{3} \\
\frac{0}{j}\end{array}$} & \multirow{2}{*}{ 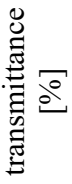 } & front & 88.4 & 78.3 & 80.1 \\
\hline & & back & 88.4 & 78.3 & 80.1 \\
\hline & \multirow{2}{*}{ 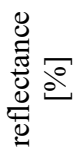 } & front & 4.5 & 17.0 & 3.3 \\
\hline & & back & 4.8 & 18.0 & 2.0 \\
\hline
\end{tabular}

Table 2. Parameters of glass systems investigated in the experimental cell obtained by calculation [14]

\begin{tabular}{|c|c|c|c|c|c|}
\hline \multirow{3}{*}{ 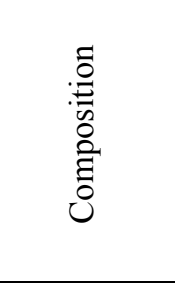 } & 1 & \multicolumn{2}{|c|}{2} & \multicolumn{2}{|c|}{3} \\
\hline & $\begin{array}{c}4-16-4- \\
16-4 \\
(44 \mathrm{~mm})\end{array}$ & \multicolumn{2}{|c|}{$\begin{array}{c}4-12-0.08- \\
12-0.08-12-4 \\
(44 \mathrm{~mm})\end{array}$} & \multicolumn{2}{|c|}{$\begin{array}{c}4-12-0.08-12- \\
4-12-0.08-12-4 \\
(60 \mathrm{~mm})\end{array}$} \\
\hline & & A & B & A & B \\
\hline Gas filling & $\begin{array}{c}\mathrm{Ar} \\
95 \%\end{array}$ & $\begin{array}{c}\mathrm{Ar} \\
95 \%\end{array}$ & $\begin{array}{c}\mathrm{Kr} \\
95 \%\end{array}$ & $\begin{array}{c}\mathrm{Ar} \\
95 \%\end{array}$ & $\begin{array}{c}\mathrm{Kr} \\
95 \%\end{array}$ \\
\hline $\begin{array}{l}\text { Low-E } \\
\text { coating } \\
\text { position }\end{array}$ & $\# 2,3,5$ & \multicolumn{2}{|c|}{$\# 2,7$} & \multicolumn{2}{|c|}{$\# 2,9$} \\
\hline $\begin{array}{l}\mathrm{U}_{\mathrm{g}} \\
{\left[\mathrm{W} /\left(\mathrm{m}^{2} . \mathrm{K}\right)\right]}\end{array}$ & 0.672 & 0.484 & 0.376 & 0.373 & 0.270 \\
\hline$\tau_{\mathrm{VIS}}[-]$ & 0.623 & 0.506 & 0.506 & 0.403 & 0.403 \\
\hline $\mathrm{g}[-]$ & 0.377 & 0.359 & 0.359 & 0.290 & 0.287 \\
\hline
\end{tabular}




\subsection{Measurement set-up and devices}

Measurements of surface temperatures were carried out on the inner surface of the glass system (see Fig. 3, 4). The following devices were used for measurements. Measurement range (MR), resolution (R) and accuracy (A) are presented in brackets for temperature sensors Ntc ZA $9400-\mathrm{FSK}\left(\mathrm{MR}=-50 \sim+125^{\circ} \mathrm{C} ; \mathrm{R}=0.01 \mathrm{~K} ; \mathrm{A}=\right.$ $\pm 0.05 \mathrm{~K})$ which were used for measuring surface temperatures. Vaisala weather station FMA510 were used to measure wind direction $\left(\mathrm{MR}=0 \sim 360^{\circ} ; \mathrm{R}=1^{\circ}, \mathrm{A}=\right.$ $\left.\pm 3^{\circ}\right)$, average and maximum wind speed $(\mathrm{MR}=0.5 \sim 60$; $\mathrm{R}=0.1 \mathrm{~m} / \mathrm{s} ; \mathrm{A}= \pm 3 \sim 5 \%)$, atmospheric pressure $(\mathrm{MR}=$ $600 \sim 1100 ; \mathrm{R}=0.1 ; \mathrm{A}= \pm 0.5 \mathrm{mbar})$, ambient air temperature $\left(\mathrm{MR}=-52 \sim+60^{\circ} \mathrm{C} ; \mathrm{R}=0.1 \mathrm{~K} ; \mathrm{A}= \pm 0.3 \mathrm{~K}\right)$ and relative humidity $(\mathrm{MR}=0 \sim 100 ; \mathrm{R}=0.1 \%, \mathrm{~A}=$ $\pm 3 \%)$, amount and intensity $(\mathrm{MR}=0 \sim 200 ; \mathrm{R}=0.01$ $\mathrm{mm} / \mathrm{h})$ of rainfall. The global solar radiation $(\mathrm{MR}=0 \sim$ $1500, \mathrm{R}=0.1 \mathrm{~W} / \mathrm{m}^{2} ; \mathrm{A}=<3 \%$ ) was measured by Pyranometer FL A628-S. All measured data were collected by the measuring instrument with datalogger function Almemo 5690-1 [15]. A two-day period was chosen from the measured data of the external and internal environment and was subsequently used as a boundary condition for the numerical calculation of the proposed glass systems.

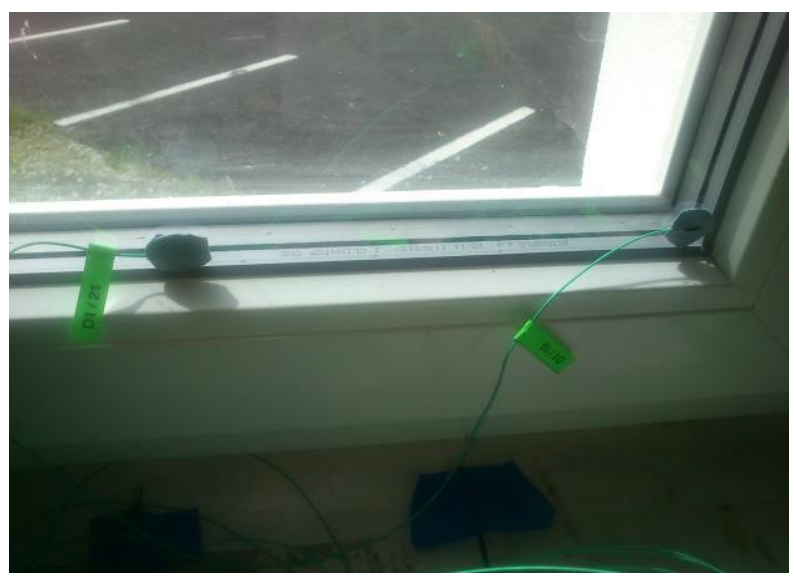

Fig. 3. Location of temperature sensors on the glass

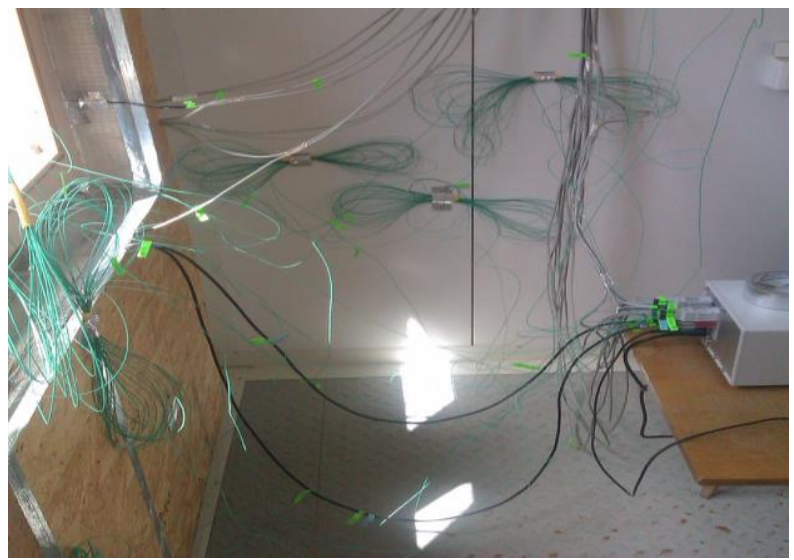

Fig. 4. Connection of surface temperature sensors to measuring instrument with data logger function Ahlborn Almemo 5690-1

\subsection{Mathematical model and simulation}

The computational model of the glass-frame detail and the window-sill contact structure as geometry and boundary with initial conditions was built. Compared to the previous model [16], the geometry of the window frame-sash was simplified. The frame-sash is not subject of task in this study. The window frame was replaced by a quasi -homogeneous hard plastic block with the intention of simplifying of provided calculation (see Fig. 5.). The calculation lasts three days including a precalculation during the day 1 to determine the initial condition. The initial calculation conditions can significantly affect the results immediately after the start of the main calculation [17]. The measured data of the parameters of the outdoor and indoor environment are considered as boundary conditions of the calculation; i.e. outdoor air temperature, global solar radiation and indoor air temperature. Achieved results are presented in Fig. 6. Long wave radiation was not measured; therefore it is not part of boundary conditions. Model calculates results according to standards [18, 19, 20]. Inputs for calculation for solar processor are:

a) solar radiation data (global solar radiation (in $\mathrm{W} / \mathrm{m}^{2}$ ) and diffuse solar radiation (in $\mathrm{W} / \mathrm{m}^{2}$ ) both on a horizontal surface),

b) north orientation against the input bitmap defined using three rotation angles,

c) geographic position of the input bitmap defined by north latitude $\left({ }^{\circ} \mathrm{N}\right)$, eastern longitude $\left({ }^{\circ} \mathrm{E}\right)$ and time zone (h E),

d) ground reflection factor,

e) per material: solar reflection factor (may be dependent on the angle of incidence defined by the solar reflection factor function) and the solar transmission factor (equals 0 for a non-transparent material),

f) sun obstacles (shadow zones of other objects around the input bitmap, defined by angular coordinates in the horizontal coordinate system).

The solar transmission factor $\tau(=\tau \mathrm{s})$ in the software Physibel- Bistra [21] was applied after subtraction of the solar reflection (which can be dependent on the angle of the solar radiation incidence). Normally the solar reflection, transmission and absorption are defined for solar radiation at normal incidence (angle of incidence $=$ $\left.0^{\circ}\right)$ :

$$
\rho 0+\tau 0+\alpha 0=1,
$$

after subtraction of reflection (as for the input value of $\tau$ in Bistra):

$$
\tau+\alpha=1,
$$

the input value of $\tau$ in Bistra can be calculated from $\rho 0$ and $\tau 0$ :

$$
\tau=\tau 0 / 1-\rho 0 .
$$



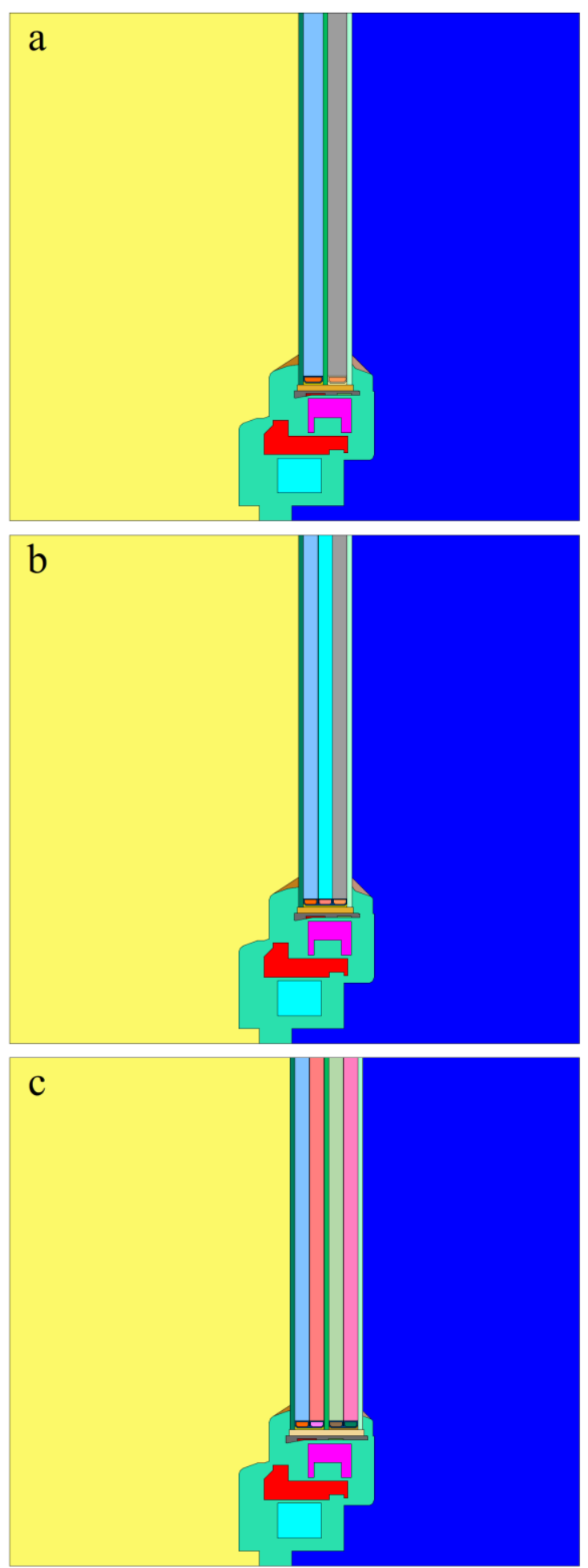

Fig. 5. Geometry of windows. a) current triple glass system; b) designed double glass system with 2 x HM88 Twin Coat used; c) designed triple glass system with $1+1 \mathrm{x}$ HM88 Twin Coat used

The model uses the following equation to calculate the heat transfer coefficient $U$ of the glazing:

$$
1 / U=1 / h_{e}+1 / h_{t}+1 / h_{i}
$$

where $h_{e}, h_{i}$ are heat transfer coefficients on the outside and inside of the structure;

$h_{t} \quad$ total thermal transmittance of the glazing. a)

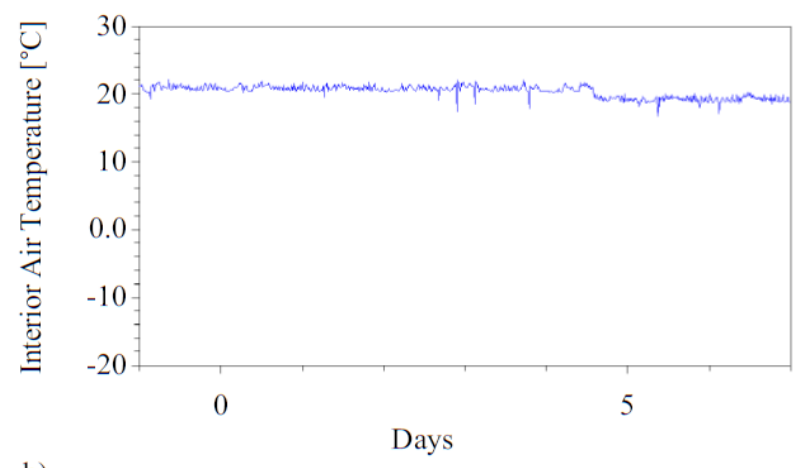

b)

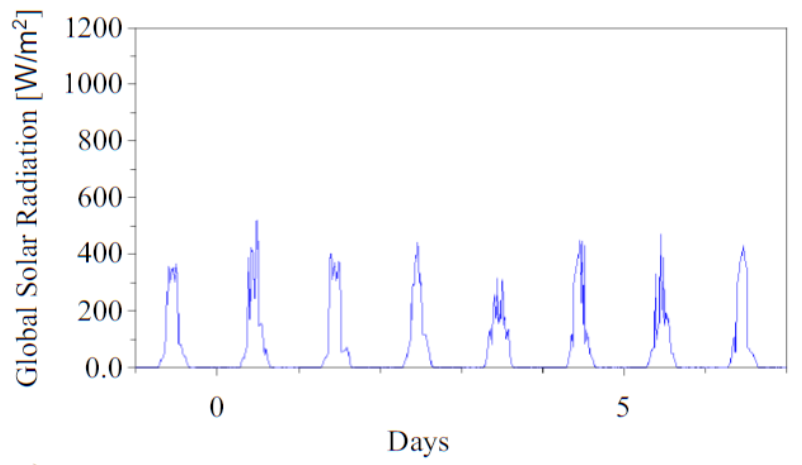

c)

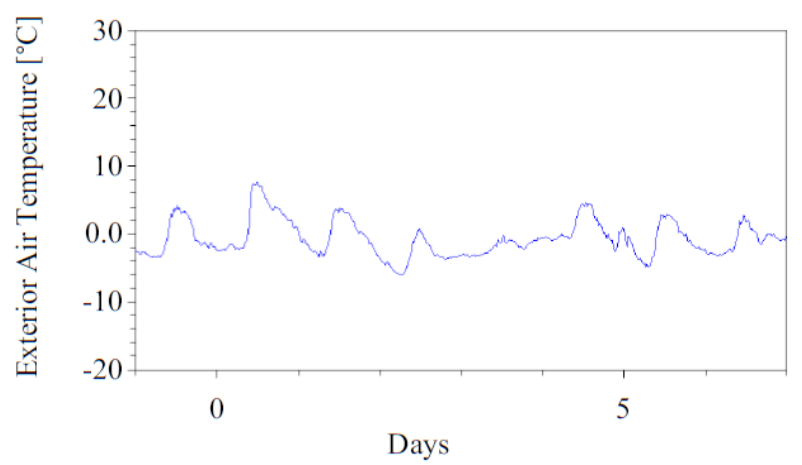

d)

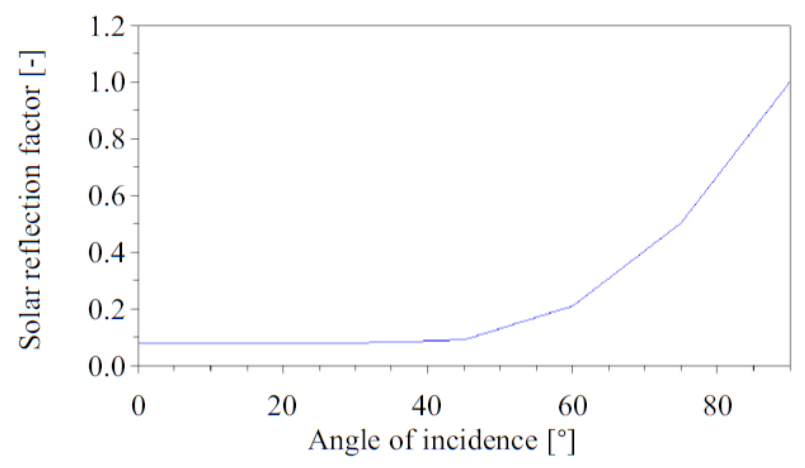

Fig. 6. Measurements in January 1-8. a) measured data of the interior air temperature; b) measured data of the global solar radiation; c) measured data of the exterior air temperature; d) dependence of solar reflection factor on the angle of incidence

The inverse value of the total transmittance of the glazing program calculates:

$$
1 / h_{t}=\sum_{1}^{N} 1 / h_{s}+\sum 1^{M} d_{j} r_{j}
$$

where $N$ is number of cavities; 
$d_{j} \quad$ thickness of each layer of material;

$r_{j} \quad$ specific heat resistance of each material

(soda-lime glass specific heat resistance is

$1.0 \mathrm{~m} . \mathrm{K} / \mathrm{W})$;

$M \quad$ number of layers.

The heat transfer of the individual cavities of the glass system is the sum of the radiation transmittance and the $U$ value of the gas in the glass system:

$$
h_{\mathrm{s}, \mathrm{k}}=h_{\mathrm{r}, \mathrm{k}}+h_{\mathrm{g}, \mathrm{k}}
$$

where $h_{\mathrm{s}, \mathrm{k}}$ is heat transfer through the cavity;

$$
\begin{array}{ll}
h_{\mathrm{r}, \mathrm{k}} & \text { radiation transmittance; } \\
h_{\mathrm{g}, \mathrm{k}} & U \text { value of gas. }
\end{array}
$$

The value of thermal transmittance caused by radiation can be calculated by:

$$
h_{t}=4 \sigma\left(1 / \varepsilon_{1, \mathrm{k}}+1 / \varepsilon_{2, \mathrm{k}}-1\right)^{-1} T_{\mathrm{m}}{ }^{3}
$$

where $\sigma$ is Stefan-Boltzmann constant;

$T_{\mathrm{m}} \quad$ mean absolute temperature of the gas-filled cavity;

$\varepsilon_{1, \mathrm{k}}, \varepsilon_{2, \mathrm{k}} \quad$ modified emissivity of the surfaces

enclosing the enclosed space between the panes glass at $T_{\mathrm{m}}$.

Model calculates thermal transmittance of gas according to standard EN 673 [11]:

$$
h_{\mathrm{g}, \mathrm{k}}=N_{\mathrm{u}} \lambda_{\mathrm{k}} / S_{\mathrm{k}}
$$

where $S_{\mathrm{k}}$ is cavity width;

$$
\begin{array}{ll}
\lambda_{\mathrm{k}} & \text { coefficient of thermal conductivity of gas; } \\
N_{\mathrm{u}} & \text { Nusselt number. }
\end{array}
$$

The Nusselt number is based on the equation:

$$
N_{\mathrm{u}}=A\left(G_{\mathrm{r}} P_{\mathrm{r}}\right)^{\mathrm{n}}
$$

where $A$ is constant;

$$
\begin{array}{ll}
G_{\mathrm{r}} & \text { Grashof number; } \\
P_{\mathrm{r}} & \text { Prandtl number; } \\
& \\
\mathrm{n} & \text { exponent. }
\end{array}
$$

Grashof and Prandtl numbers are based on the equations:

$$
\begin{aligned}
& G_{\mathrm{r}}=9.81 s^{3} \Delta T \rho^{2} /\left(T_{\mathrm{m}} \mu^{2}\right) \\
& P_{r}=\mu_{\mathrm{c}} / \lambda
\end{aligned}
$$

where $\Delta T$ is the temperature difference between the

glass surfaces enclosing the gas-filled
cavity,
$\rho \quad$ density,
$\mu \quad$ dynamic viscosity,
$c \quad$ specific heat capacity,
$T_{\mathrm{m}} \quad$ mean temperature.

The parameters of the mathematical model were set based on the measured surface temperature data of the glass system. The model can therefore be considered verified and suitable for validation.

\section{Results and discussion}

Numerical analysis results obtained from dynamic simulation applying software Physibel- Bistra [21] show a correlation between calculation and measured data. The influence of global solar radiation on the inner surface temperature of the glass system as well as on the temperature of the indoor environment is evident. Before quantifying the proposed glass systems, it is necessary to set up and fine-tune the mathematical model, its response to boundary conditions. The calculation requires definition of the material and its basic physical properties (coefficient of thermal conductivity, specific heat capacity, density and emissivity of the surface) and energy properties (reflectance, absorption and transmittance of the solar radiation). The values of reflectance, absorption and transmittance of the solar radiation are taken from the previous calculation results of Window 7.4.14. The observed point in the measurement and calculation is located in the middle of the surface of inner glass pane, so result is not affected by the spacer or window frame. Systems 1, 2A and 3A were simulated, see also Table 2., Thermal-optical properties of systems $2 \mathrm{~B}$ and $3 \mathrm{~B}$ were determined under steady-state conditions for comparison purposes. The profile of the measured and calculated values of the current glass system has a similar trend (dashed lines in Fig. 7.). The mathematical model responds appropriately to the global solar radiation present. The difference (averagely appx. $1^{\circ} \mathrm{C}$ ) that can be observed especially when sunlight is absent may be due to the absence of long wave radiation data. Long wave radiation was not measured. The calculated surface temperatures of the glass system 2 at the time of exposure to the sun show high differences from the actual glass system 1 , the trend being the same. Thus, replacing the low-emissive middle glass pane with two low-emissivity films did not bring about a reduction in surface temperatures on the inner surface of the glass. In the case of the results of the proposed glass system 3 , a change in trend compared to alternatives 2 and 3 can be observed (dotted lines in Fig. 7.). Surface temperatures increased by an average of $2^{\circ}$ $\mathrm{C}$ during the absence of the solar radiation. The effect of the sun on surface temperatures at the time of shining is significantly lower than in systems 1 and 2 . The course thus confirms the improvement of the thermal insulation 
ability of the glass system. When argon was replaced by a krypton in alternative $3 \mathrm{~B}$, the simulation results the increase of surface temperatures which would be even more noticeable. Comparison of achieved results is shown in detail Fig. 7. On the left y-axix is scale of temperatures and the right $\mathrm{y}$-axis represents scale of the solar global radiation.

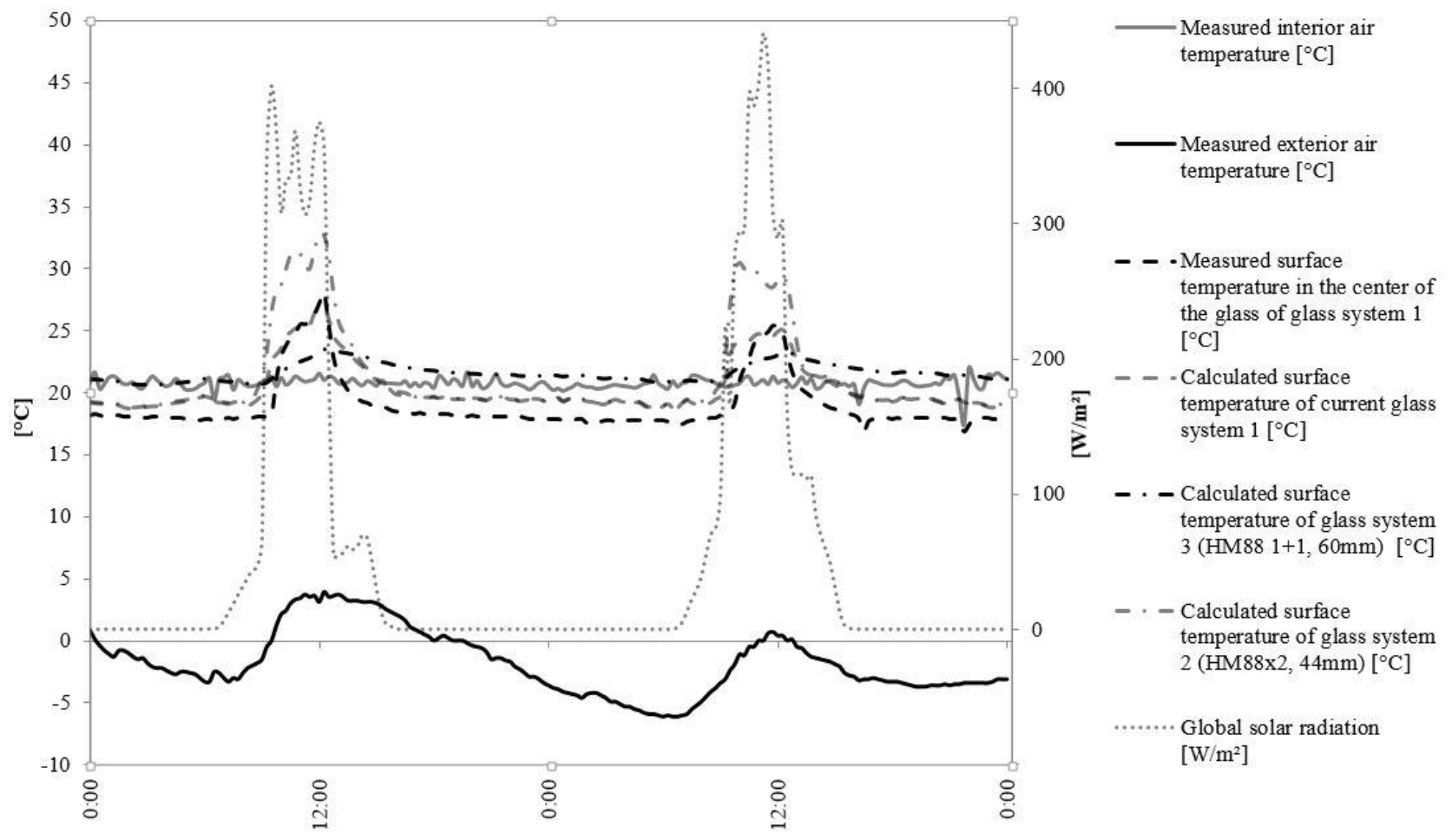

Fig. 7. Profile of measured and calculated values of surface temperatures of glass systems 1,2 and 3 during the monitored period on the base of boundary conditions

\section{Conclusion}

The study answers the questions raised in the introduction following mentioned previous results and conclusions. Through the dynamic simulation, this study provides insight into the behaviour of the window structure before and after replacing the glass system. The setup of the mathematical model appears to be relatively accurate, but the presence of long wave data would yield more accurate results. The influence of selective layers on the thermal-optical properties of the glazing has been confirmed, and when comparing the current (1) and proposed (3A) glass system, without an influence of the sun irradiation, the immediate difference in surface temperature on the inner glass is averagely $1.9^{\circ} \mathrm{C}$. The heat transfer coefficient is also significantly influenced by the increase in the thickness of the glass system and the addition of a $12 \mathrm{~mm}$ thick gap filled with argon. The calculation shows a decrease of $U$ by $0.299 \mathrm{~W} /\left(\mathrm{m}^{2} . \mathrm{K}\right)$. Compared to alternative 3B (krypton fill), the difference is $0.402 \mathrm{~W} /\left(\mathrm{m}^{2} \cdot \mathrm{K}\right)$. The difference seems even more interesting considering the heat transfer coefficient of the original glass system $\left(U=0.672 \mathrm{~W} /\left(\mathrm{m}^{2} . \mathrm{K}\right)\right)$. The resulting value of the heat transfer coefficient, which approximates the values of the external wall, is interesting from the point of view of the current heat protection requirements of buildings, but at the same time it indicates that it will prevent the penetration of the desired solar gain during sunny winter days. The same situation occurs in case of desirable night cooling of the interior during summer nights. The solution is outlined in the design of a glass system capable of responding to changes in weather conditions after evaluating the impact on indoor thermal comfort.

This research was supported by the Slovak Scientific Grant Agency (VEGA) under grant numbers 2/0017/20 and 1/0389/17.

\section{References}

1. D. Zekraoui, N. Zemmouri, Energy Proceedia 115, 162-172 (2017)

2. S. Grynning, A. Gustavsen, B. Time, B. P. Jelle, Energy and Build. 61, 185-192 (2013)

3. A. Ghosh, B. Norton, A. Duffy, Cept University, 1-8 (2014)

4. A. Ghosh, B. Norton, A. Duffy, Sol. Energy Mater. Sol. Cells 161, 424-431 (2017)

5. A. Ghosh, B. Norton, A. Duffy, Sol. Energy Mater. Sol. Cells 160, 134-140 (2017)

6. A. Ghosh, B. Norton, Sol. Energy Mater. Sol. Cells 163, 178-184 (2017)

7. A. Ghosh, B. Norton, A. Duffy, Appl. Energy 169, 469-480 (2016) 
8. A. Ghosh, B. Norton, A. Duffy, Appl. Energy 159, 362-369 (2015)

9. E. Moretti, E. Belloni, E. Lascaro, Energy Procedia 78, 340-345 (2015)

10. I. El-Darwish, M. Gomaa, Alexandria Eng. J. 56, 579-589 (2017)

11. A. Radwana, A.F. Radwan, A.A. Hanafy, M. Elhelw, A.H.A. El-Sayed, Alexandria Eng. J. 55, 3061-3071 (2016)

12. D. Katunsky, M. Zozulák, K. Kondas, J. Simicek, Advanced Materials Res. 899, 147-150 (2014)

13. H. Hens, Applied Building Physics, Boundary Conditions, (Ernst \& Sohn, Berlin, 2010)

14. Window 7.4.14: NFRC Simulation manual, Lawrence Berkley laboratory, (2017)

15. AHLBORN Product Catalogue: Measuring instruments and sensors, (2011/2012)

16. S. Bizonova, M. Bagona, Therm. Prot. of Build., 124-127 (2019)

17. M. Zozulak, M. Vertal, D. Katunsky, Buildings 9, 178 (2019)

18. EN 673 Glass in building - Determination of thermal transmittance ( $U$ value) - Calculation method, (1997)

19. EN ISO 13792 Thermal performance of buildingsCalculation of internal temperatures of a room in summer without mechanical cooling- Simplified methods, (2005)

20. EN 14501 Blinds and shutters. Thermal and visual comfort. Performance characteristics and classification, (2005)

21. Physibel Software, User Manual for Physibel, (2013) 